\title{
Experimental Investigation on Compressive Strength Enhancement of Geopolymer Paste Fly Ash/ Slag Based Cured at Ambient Condition
}

\author{
Wrood H. Sachet ${ }^{1}$, Wissam D. Salman ${ }^{2}$, Safie Mahdi Oleiwi ${ }^{3}$ and Dia Eddin Nassani ${ }^{4}$ \\ 1,2,3 Department of Civil Engineering, College of Engineering, University of Diyala \\ ${ }^{4}$ Department of Civil Engineering, Hasan Kalyoncu University, Gaziantep, Turkey \\ emails:WroodHameed@yahoo.com,dr_wissam80@yahoo.com, safiemahdi@yahoo.com and \\ diaeddin.nassani@hku.edu.tr.
}

\begin{abstract}
In this paper, the effects of ground granulated blast furnace slag (GGBFS) content proportion on the development of compressive strength of geopolymer pastes were studied. Eleven geopolymer pastes mixes replacement $(0 \%$ to $100 \%)$ by increment $(10 \%)$ of binder(Fly Ash) by GGBFS with three mini-size specimens (50-mm cube) compression tests were conducted at ambient condition $\left(30 \pm 2{ }^{\circ} \mathrm{C}\right)$. Class F-fly ash (FA) and GGBFS were used as aluminosilicate source. The alkaline activator was a combine of sodium silicate (SS) solution and sodium hydroxide (SH) solution with (SS/SH) ratio of (2.0) and molarity of sodium hydroxide of (10M). Based on the test results, it was find that the addition of ground granulated blast furnace slag (GGBFS) to geopolymer paste based fly ash caused increase significantly of compressive strength when cured at ambient condition, and the optimum mix was found to have GGBFS content of $100 \%$, can be improved the compressive strength as high as (74\% and $62 \%)$ at 7 and 28 days respectively. The reason for this trend is that the increasing forming of calcium silicate hydrate C-S-H gel of geopolymer pastes containing a large amount of GGBFS caused more denser microstructure. Lastly, it is worth noting that this test methodology used in this study is for the purpose of determining the best ratio of slag replacement with fly ash in geopolymer paste, to give the highest improvement ratio in compressive strength compared with the reference (Fly Ash based geopolymer paste).
\end{abstract}

Keywords: fly ash, slag, geopolymer paste, compressive strength and ambient curing.

Paper History: (Received:11-3-2020; Accepted:31-52020).

\section{Introduction}

Currently, climate change due to global warming occurs is proven by scientific consensus overwhelming majority. Climate change is one of the major sociality politically, economically and environmentally affair that will own long term impact over living creatures on this whorl [1]. The climate change is due to the resurrection of greenhouse gases, like carbon di-oxide $\mathrm{CO}_{2}$, into the atmosphere through human activities. Among other greenhouse gases, carbon di-oxide $\mathrm{CO}_{2}$ forms about $68 \%$ of universal warming. The Manufacture of Ordinary Portland cement OPC is responsible for about 6-8\% of all $\mathrm{CO}_{2}$ emissions, because the cement production process emits a huge amount of carbon di-oxide $\mathrm{CO}_{2}$ to the atmosphere that significantly contribute greenhouse gas emissions [2,3,4]. It was evaluated that for one ton of Ordinary Portland cement manufacture one ton of carbon di-oxide $\mathrm{CO}_{2}$ is released into the atmosphere, this is creating a challenging situation in the world of concrete $[1,2,5,6]$. In view of this, various researchers have attractive extensive research attention to utilize cementitious properties of fly ash and ground granulated blast furnace slag (GGBFS) by-products industries to develop sustainable alternatives for conventional cement [7]. On the other hand, the abundance and availability of slag and fly ash worldwide promote to usage these byproducts, as performance enhancer and partially or totally replacing the OPC [8]. Therefore, the French researcher Davidovits in 1978 invented geopolymer material [3,5]. Geopolymer materials have a major ability to substitution OPC raw source materials and greatly reducing energy consumes and emission of carbon di-oxide $\mathrm{CO}_{2}$ [7]. Ingredients of the geopolymer materials are important source of aluminosilicate that react with alkaline activator via polymerization process $[1,7,9]$. Hence, It was found that the chemical composition of source materials and alkaline activators have been influenced significantly on the mechanical properties of the geopolymer materials $[7,10,11]$. However, to access high mechanical properties of geopolymer based- fly ash essentially required high temperature (i.e. over $40{ }^{\circ} \mathrm{C}$ ) in early curing stage to achieve enough rate of strength development [12-18]. This limited the utilization of geopolymer with structural construction. Therefore, a significant amount of research has been conducted to explore the increase compressive strength of geopolymer with ambient curing. That have been achieved in geopolymers by improving the microstructure of geopolymer matrix after addition of more calcined source materials. So, the previous studied reported that to reduce the requirement of elevated curing temperature, was adding calcium-carrying materials such as ground-granulated blast furnace slag (GGBFS) that have been added to geopolymers incorporating GGBS in fly ash-based geopolymer mortar due to increase in 
compressive strength but accelerate setting times, and reduce workability, to improve it was adding superplasticizers in mixes [18]. Hence, predicts incorporation of GGBFS in the geopolymer specimens is attributed to the forming of more compact microstructure of the binder $[19,20]$. In the latter case, is produced a C$\mathrm{S}-\mathrm{H}$ gel as a hydration process result, in addition to $\mathrm{N}$ A-S-H gel at the early duration $[3,9,10,11]$. To date, there are not any published studies on the compressive strength of the geopolymer paste made of replacement ratio (i.e. $50 \%$ to $100 \%$ ) of fly ash by slag under ambient condition. Accordingly, the aim of this work is to show the effectiveness of GGBFS incorporation with fly ash type F on the compressive strength development of geopolymer paste when cured under ambient condition. This paper, illustrate the first experimental study on producing geopolymer paste over extensive range of the fully replacement fly ash with slag from $0 \%$ to $100 \%$ by increment $10 \%$, thus introduced as novel approaches to promote compressive strength of the geopolymer paste based on slag at ambient condition. That made it provides of the potential utilization of geopolymer paste as an in situ construction material cured at ambient temperatures.

\section{Experimental Scheme}

\subsection{Material}

Eleven types of geopolymer paste (GP) mixture were produced to analysis the effect of GGBS on the compressive strength development at the same flowability. Ground granulated blast furnace slag (GGBFS) and low calcium 'Class F' fly ash (FA) according to ASTMC618 [21] were utilized as binder materials in current research. Table 1 shows the X-Ray Fluorescence (XRF) for chemical oxides composition of the fly ash (FA) and slag. That was conducted at the Science and Technology Center in Baghdad.

Activator solution was admixture of sodium silicate (SS) solutions $\left(\mathrm{Na}_{2} \mathrm{SiO}_{3}\right)$ and sodium hydroxide $(\mathrm{SH})$ solutions $(\mathrm{NaOH})$ (Kuwait origin). Chemical composition of sodium silicate (SS) was obtained from the regional source that shown in Table 2 . The sodium hydroxide $(\mathrm{SH})$ had $95-97 \%$ purity and (10M) was chosen as a molarity, was prepared by melting with distilled water, which had been suggested to obtain sensible compressive strength development in another research [22]. The materials used are given in Figure 1.

Table 1: The chemical composition of GGBFS and FA.

\begin{tabular}{ccc}
\hline Chemical oxides analyze & FA $(w . \%)$ & GGBFS $(w . \%)$ \\
$\mathrm{SiO}_{2}$ & 11.75 & 9.808 \\
$\mathrm{Al}_{2} \mathrm{O}_{3}$ & 2.513 & 1.305 \\
$\mathrm{CaO}$ & 1.175 & 25.35 \\
$\mathrm{Fe}_{2} \mathrm{O}_{3}$ & 6.461 & 0.9038 \\
$\mathrm{MgO}_{\mathrm{SO}}$ & 0.106 & 0.36 \\
$\mathrm{~K}_{2} \mathrm{O}$ & 0.1303 & 0.4169 \\
$\mathrm{Na}_{2} \mathrm{O}$ & 1.763 & 0.6969 \\
$\mathrm{LOI}$ & $<0.3$ & $<0.39$ \\
Specific gravity & 1.57 & 1.64 \\
\end{tabular}

Note: w. $\%$, that mean a percentage of the compound weight.

Table 2: The chemical composition of sodium silicate.

\begin{tabular}{ccccc}
\hline chemical composition & $\mathrm{Na}_{2} \mathrm{O}$ & $\mathrm{SiO}$ & specific gravity & viscosity \\
\hline Sodium silicate $(\%)$ & $13-13.5$ & $29-32$ & $1.54-1.552$ & $620-1180$ \\
\hline
\end{tabular}




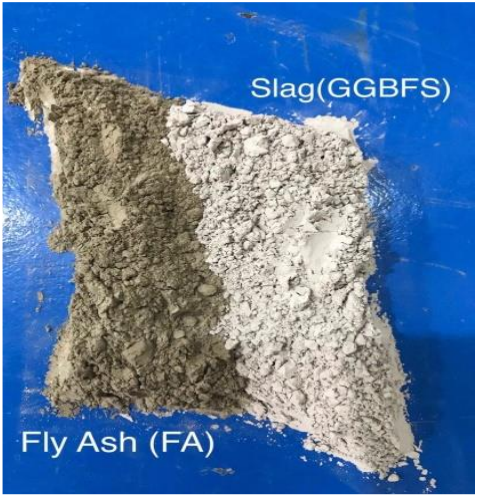

\subsection{Preparing Geopolymer Mixture}

Totally eleven geopolymer paste (GP) mixtures were prepared. Table 3 shows the proportions of the mixtures. The primary binder had been FA with exchange ( $\% 0$ to $100 \%$ increment $10 \%$ ) by slag with increasing activator solution to obtain the same flowability of geopolymer paste, because the increasing of slag replacement ratio
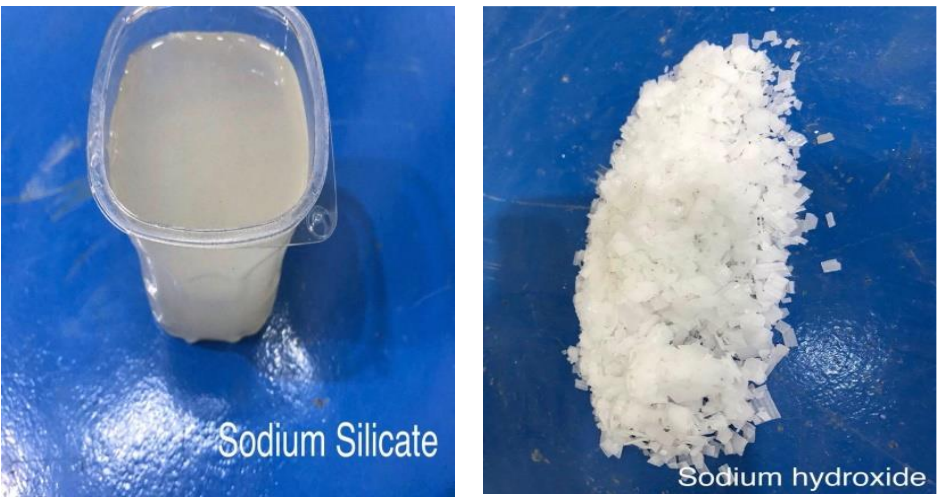

Figure 1: The materials used.

addition lead to decreasing the flowability. The alkaline activator was prepared at least 24 hours before casting. The mass ratio of sodium silicate (SS) solution to sodium hydroxide ( $\mathrm{SH}$ ) solution ( $\mathrm{SS} / \mathrm{SH})$ was constant as (2). In this study, concentration of $(\mathrm{NaOH})$ solution is taken as $(10 \mathrm{M})$, at each mixture. The samples were labeled according to the (GGBFS) proportion usage in the mixture.

Table 3: Mixture proportions of geopolymer pastes.

\begin{tabular}{|c|c|c|c|c|c|}
\hline \multirow[b]{2}{*}{ Mixture } & \multicolumn{2}{|c|}{ Binder $(w \%)$} & \multirow[b]{2}{*}{$\mathrm{F} / \mathrm{B}$} & \multicolumn{2}{|c|}{ Solution $\left(\mathrm{kg} / \mathrm{m}^{3}\right)$} \\
\hline & FA & GGBFS & & $\begin{array}{l}\mathrm{NaOH} \\
(10 M)\end{array}$ & $\mathrm{Na}_{2} \mathrm{SiO}_{3}$ \\
\hline GP- F100S0 ${ }^{a}$ & 100 & 0 & 0.330 & 236 & 474 \\
\hline GP- F90S10 & 90 & 10 & 0.360 & 236 & 474 \\
\hline GP- F80S20 & 80 & 20 & 0.387 & 236 & 474 \\
\hline GP- F70S30 & 70 & 30 & 0.418 & 236 & 474 \\
\hline GP- F60S40 & 60 & 40 & 0.448 & 236 & 474 \\
\hline GP- F50S50 & 50 & 50 & 0.478 & 236 & 474 \\
\hline GP- F40S60 & 40 & 60 & 0.508 & 236 & 474 \\
\hline GP- F30S70 & 30 & 70 & 0.518 & 236 & 474 \\
\hline GP- F20S80 & 20 & 80 & 0.528 & 236 & 474 \\
\hline GP- F10S90 & 10 & 90 & 0.538 & 236 & 474 \\
\hline GP- F0S100 & 0 & 100 & 0.548 & 236 & 474 \\
\hline
\end{tabular}

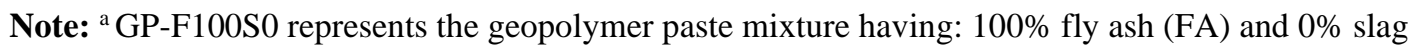
(GGBFS). F/B represents the fluid to binder ratio.

\subsection{Mixing and Curing}

Firstly, The activator solution was prepared in the laboratory at least 24 hours before using. To get the required molarity sodium hydroxide flakes were dissolved in distilled water and mixing sodium silicate (SS) solution and sodium hydroxide ( $\mathrm{SH}$ ) solutions at the desired ratio about half hour before factual mixture of the geopolymer paste $[9,23]$.

This was followed by putting weighted Fly ash and limited replacement proportion of GGBFS for each mix and mixed together, by using electric-mixer for 2 minutes. Then, adding the activator solutions to the dry mixture and the mixing continued further for about 4 minutes to produce fresh geopolymer paste $[9,10,23]$. Accordance to the ASTM C109 [24], three standard specimens mold $(50 \times 50 \times 50 \mathrm{~mm}$ cubes $)$ were prepared to estimate the compressive strength. The GP specimens were casting in two layers and for compact the specimens using a vibration table for about 30 second. To avoid excessive moisture loss of the GP specimens were completely covered by plastic bagging through curing duration and cured at ambient temperature $(30 \pm 2$ $\left.{ }^{\circ} \mathrm{C}\right)$. Then, demolded and storage in room temperature even testing day. At the age 7 and 28 days compressive strength was tested. Figure 2 shows stages of the experimental work. 

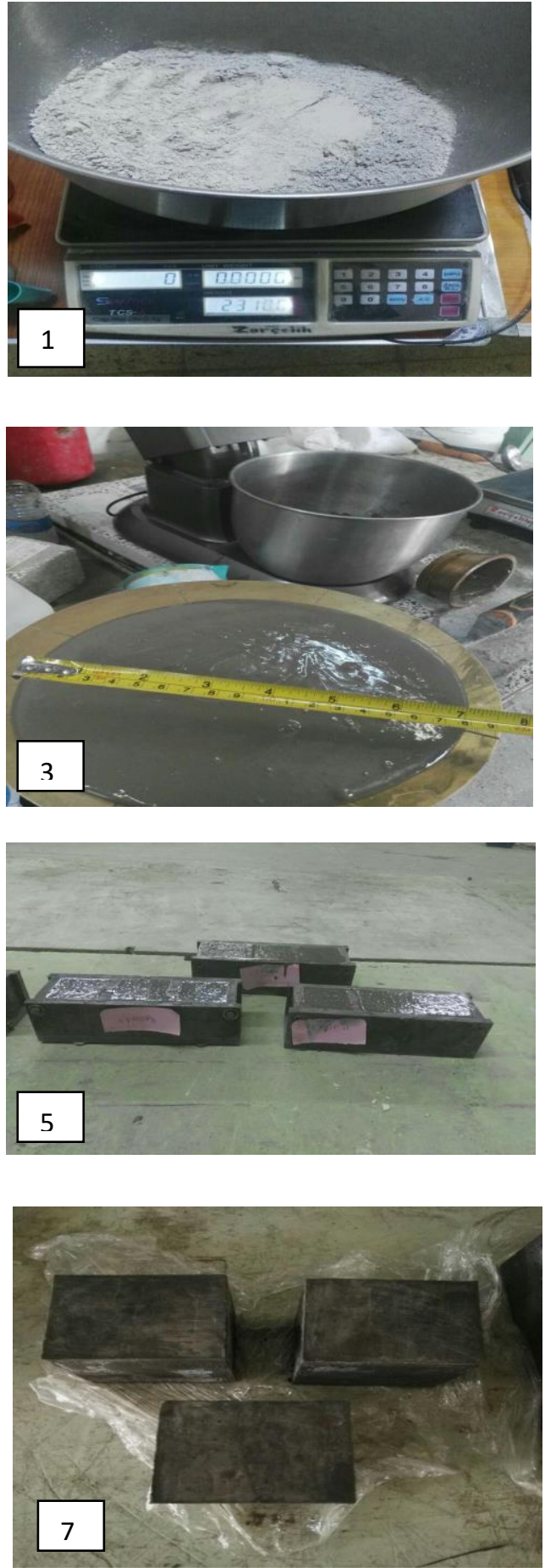
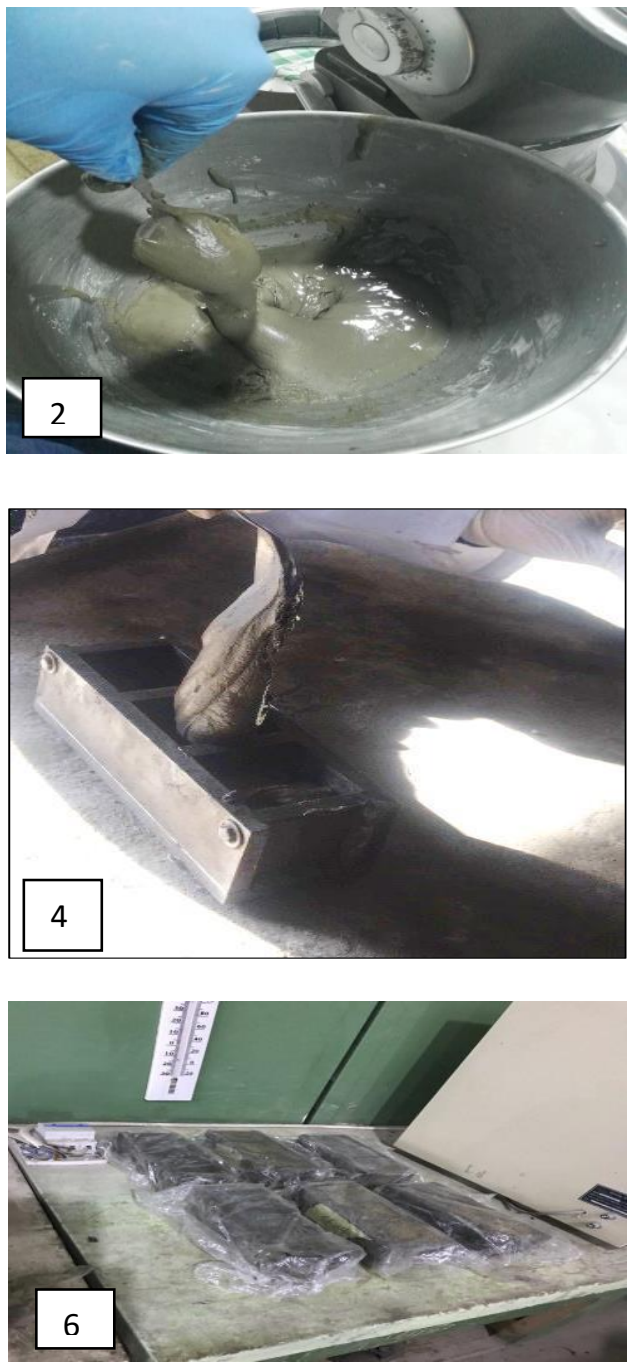

Figure 2: Experimental work stages (casting and curing).

\section{Results and discussion}

\section{Compressive strength development}

Compressive Strength is the most important properties usage as an indicator of the other mechanical properties .Where the other properties frequently connected well with the compressive strength .Figure 3 shown the impact of the various concentrations of GGBFS on the compression in (7 and 28) days. The graph shows that the increase GGBFS content in the mix (three cubes of specimens cured at ambient temperature) leads to increase the compressive strength development. Figure 4, shows that the mixture containing $100 \%$ slag have biggest compressive strengths than the other mixtures, its highest than the reference ( Fly ash only ) mixture by (74\% and $62 \%$ ) at (7and 28) days respectively. Generally, it was noticed that there was a significant development in compression with the raising of percentage GGBFS in all curing period, when compared with the reference mix. 


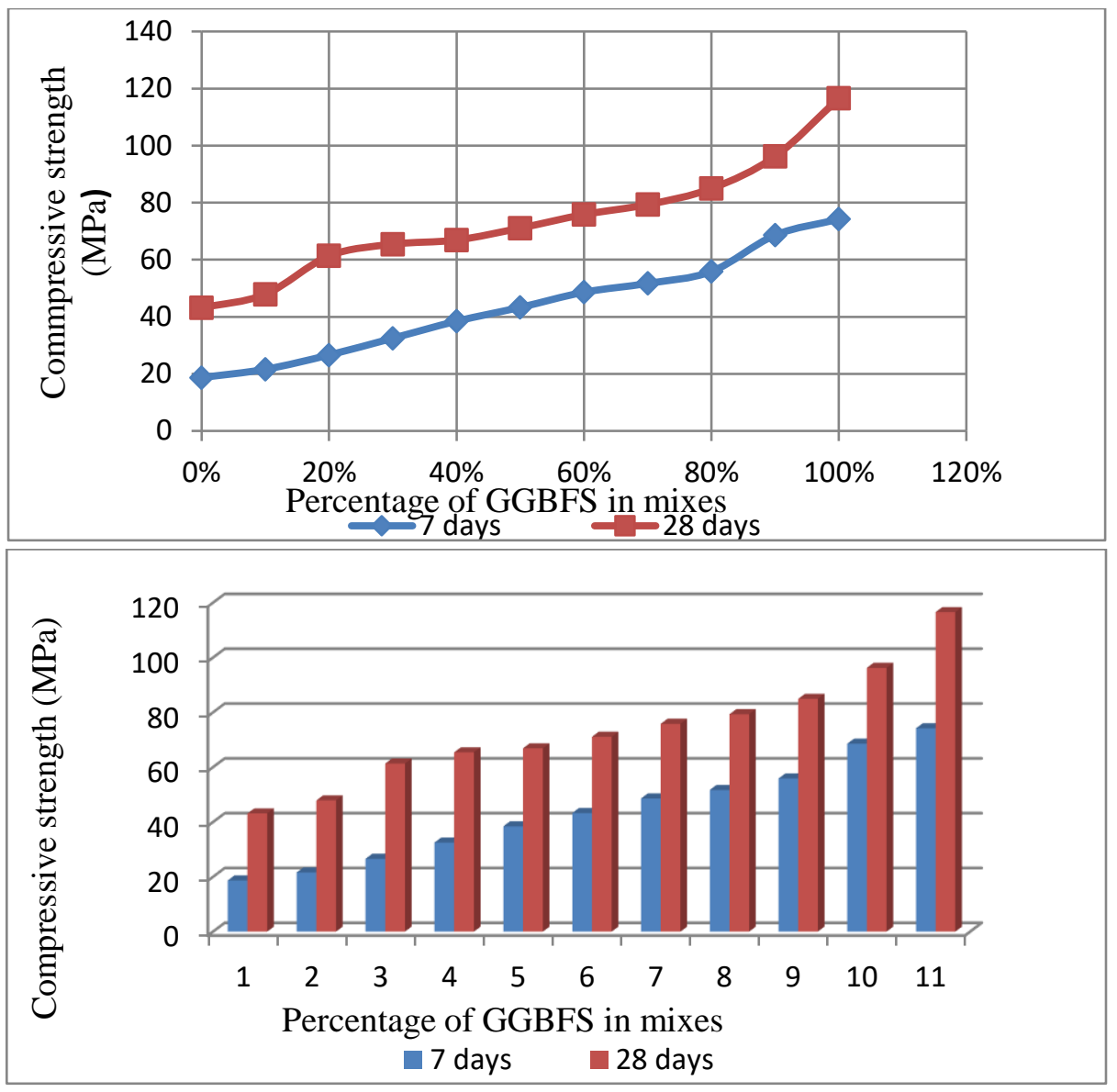

Figure 3: Compressive strength development.

Compressive strength of geopolymer paste for mixes containing $(10 \%, 20 \%, 30 \%, 40 \%, 50 \%, 60 \%, 70 \%, 80 \%$, $90 \%$, and $100 \%$ ) GGBFS, at 7 and 28 days, were increased by percentage $(14 \%, 29.7 \%, 42.4 \%, 51.3 \%$, $56.8 \%, 61.5 \%, 63.83 \%, 66.53 \%, 72.7 \%$, and $74.8 \%)$ and $(10 \%, 29 \%, 34 \%, 35.5 \%, 39.3 \%, 43.1 \%, 45.6 \%, 49.2 \%$, $55.16 \%$, and $62 \%$ ) respectively. The reason for this trend is that the increasing forming of calcium silicate hydrate C-S-H gel of geopolymer pastes containing a large amount of GGBFS caused more denser microstructure [9, 14]. The variation of compressive strength at 7 days had a higher trend compared with the 28 days due to formation sufficient amount of calcium silicate hydrate gel $(\mathrm{C}-\mathrm{S}-\mathrm{H})$ as a result of $\mathrm{CaO}$ content in GGBFS is high along with sodium aluminate silicate hydrate gel $(\mathrm{N}-\mathrm{A}-\mathrm{S}-\mathrm{H})$ in microstructure to become very denser in early stage.

\section{Conclusions}

Eleven geopolymer paste GP mixtures were tested to investigate the impact of different slag content at room temperature. The following conclusions can be summarized as follows:

1. Addition of ground granulated blast furnace slag (GGBFS) to geopolymer paste based fly ash caused increase significantly in compressive strength when cured at ambient condition.
2. Ambient curing temperatures for in situ construction could be used for geopolymer paste with $50 \%$ to $100 \%$ GGBS content.

3. An increase in the alkali-activator solution content produced a more flowability of geopolymer paste that required longer durations to set.

4. The optimum replacement percentage of GGBFS in mixture which shown the better increment in compressive strength is $100 \%$ of binder. Compression at the optimal proportion mixture of GGBFS was bigger than the reference by $(74 \%$ and $62 \%)$ at 7 and 28 days respectively.

\section{Acknowledgment:}

My gratitude and appreciation to the boss of the department of construction laboratories, at the college of engineering, Diyala University, for the support me to conduct this research program.

\section{Reference}

[1]. Reed, M., Lokuge, W. and Karunasena, W., 2014. Fibre-reinforced geopolymer concrete with ambient curing for in situ applications. Journal of materials science, 49(12), pp.4297-4304. 
[2]. Bhikshma, V., KOTI, R.M. and SRINIVAS, R.T., 2012. An experimental investigation on properties of geopolymer concrete (no cement concrete).

[3]. Saha, S. and Rajasekaran, C., 2017. Enhancement of the properties of fly ash based geopolymer paste by incorporating ground granulated blast furnace slag. Construction and Building Materials, 146, pp.615620.

[4]. Ibrahim, A.M., Ali, N.K. and Salman, W.D., 2013. Flexural capacities of reinforced concrete two-way bubbledeck slabs of plastic spherical voids. Diyala Journal of Engineering Sciences, 6(2), pp.9-20.

[5]. Shuaibu, R.A., 2014. Compressive Strength of Low Calcium Fly Ash Geopolymer Concrete-A Review. International Journal of Emerging Technology and Advanced Engineering, 4, pp.463-470.

[6]. Vijai, K., Kumutha, R. and Vishnuram, B.G., 2012. Properties of glass fibre reinforced geopolymer concrete composites.

[7]. Alzeebaree, R., Çevik, A., Nematollahi, B., Sanjayan, J., Mohammedameen, A. and Gülşan, M.E., 2019. Mechanical properties and durability of unconfined and confined geopolymer concrete with fiber reinforced polymers exposed to sulfuric acid. Construction and Building Materials, 215, pp.1015-1032.

[8]. Abhilash, P., Sashidhar, C. and Reddy, I.R., 2016. Strength properties of Fly ash and GGBS based Geopolymer Concrete. International Journal of ChemTech Research, ISSN, pp.0974-4290.

[9]. Deb, P.S., Nath, P. and Sarker, P.K., 2014. The effects of ground granulated blast-furnace slag blending with fly ash and activator content on the workability and strength properties of geopolymer concrete cured at ambient temperature. Materials \& Design (19802015), 62, pp.32-39.

[10]. Hadi, M.N., Zhang, H. and Parkinson, S., 2019. Optimum mix design of geopolymer pastes and concretes cured in ambient condition based on compressive strength, setting time and workability. Journal of Building Engineering, 23, pp.301-313.

[11]. Eswaramoorthi, P. and Arunkumar, G.E., 2014. Fibers study on properties of geopolymer concrete with polypropylene. International Refereed Journal of Engineering and Science, 3(2), pp.60-75.

[12]. Babu, D.V., 2018. Assessing the performance of molarity and alkaline activator ratio on engineering properties of self-compacting alkaline activated concrete at ambient temperature. Journal of Building Engineering, 20, pp.137-155.

[13]. Reddy, M.S., Dinakar, P. and Rao, B.H., 2018. Mix design development of fly ash and ground granulated blast furnace slag based geopolymer concrete. Journal of Building Engineering, 20, pp.712-722.

[14]. Nath, P. and Sarker, P.K., 2014. Effect of GGBFS on setting, workability and early strength properties of fly ash geopolymer concrete cured in ambient condition. Construction and Building Materials, 66, pp.163-171.

[15]. Kumar, S., Kumar, R. and Mehrotra, S.P., 2010. Influence of granulated blast furnace slag on the reaction, structure and properties of fly ash based geopolymer. Journal of materials science, 45(3), pp.607615.

[16]. Ozbakkaloglu, T. and Xie, T., 2016. Geopolymer concrete-filled FRP tubes: Behavior of circular and square columns under axial compression. Composites Part B: Engineering, 96, pp.215-230.

[17]. Ali, H.A. and Salman, W.D., 2020. Behavior of Hybrid CRRP-Concrete-Steel Double Skin Tubular Column under Axial Load. DIYALA JOURNAL OF ENGINEERING SCIENCES, 13(1), pp.106-117.

[18]. El-Hassan, H. and Ismail, N., 2018. Effect of process parameters on the performance of fly ash/GGBS blended geopolymer composites. Journal of Sustainable Cement-Based Materials, 7(2), pp.122-140.

[19]. Hadi, N.S., Salman, W.D. and Oleiwi, S.M., 2020, March. Production of geopolymer adhesive paste material for NSM technique. In AIP Conference Proceedings (Vol. 2213, No. 1, p. 020150). AIP Publishing LLC.

[20]. Wardhono, A., Law, D.W., Sutikno and Dani, H., 2017, September. The effect of slag addition on strength development of Class C fly ash geopolymer concrete at normal temperature. In AIP Conference Proceedings (Vol. 1887, No. 1, p. 020030). AIP Publishing LLC.

[21]. Astm, C., 1985. 618, Standard Specification for Fly Ash and Raw or Calcined Natural Pozzolan for Use as a Mineral Admixture in Portland Cement Concrete. Ann. Book of ASTM Standards, Section, 4.

[22]. Gülşan, M.E., Alzeebaree, R., Rasheed, A.A., Niş, A. and Kurtoğlu, A.E., 2019. Development of fly ash/slag based self-compacting geopolymer concrete using nanosilica and steel fiber. Construction and Building Materials, 211, pp.271-283.

[23]. Hadi, N.S., Salman, W.D. and Oleiwi, S.S.M., 2019, August. Effect of Nano-Silica and Micro Steel Fiber on Compressive Strength Development of Fly Ash Geopolymer Paste Cured Under Ambient Temperature. In IOP Conference Series: Materials Science and Engineering (Vol. 584, No. 1, p. 012010). IOP Publishing.

[24]. ASTM, A., 2013. Standard test method for compressive strength of hydraulic cement mortars (using 2-in. or [50-mm] cube specimens). Annual Book of ASTM StandardsAnnual Book of ASTM Standards, 4(1), pp.1-9. 